\title{
REDES SOCIAIS E CAPITAL SOCIAL DE CATADORES
} ASSOCIADOS

\author{
REDES SOCIALES Y EL CAPITAL SOCIAL DE COLECTORES ASSOCIADOS \\ SOCIAL NETWORKS AND SOCIAL CAPITAL OF ASSOCIATED STREET WASTE \\ COLLECTORS
}

http://dx.doi.org/10.1590/1807-0310/2018v30173663

Natalia Lopes Braga ${ }^{1}$, Regina Heloisa Maciel ${ }^{1}$ e Renata Guimarães de Carvalho ${ }^{2}$

${ }^{1}$ Universidade de Fortaleza, Fortaleza/CE, Brasil

${ }^{2}$ Universidade Federal do Ceará, Sobral/CE, Brasil

\begin{abstract}
RESUMO
O artigo objetivou investigar a formação de redes sociais de trabalho, e o consequente fomento de capital social, entre membros de uma associação de catadores de materiais recicláveis. Através de entrevistas e do uso de softwares especializados, foi realizado um mapeamento das redes sociais de seis catadores. Os resultados mostraram que as redes dos associados caracterizam-se por um elevado nível de homofilia de parentesco, com a presença sobretudo de laços fortes e com alto índice de localismo. A família, amigos e vizinhos oferecem mais benefícios do que o fato de ser associado, estando nessas relações a maior fonte de apoio e recursos dos catadores. As características das redes sociais dos associados, a saber, com significativo localismo, homofilia, pouca diversificação e sem interação entre os trabalhadores, revelam um contexto de trabalho que não oferece subsídios para a diminuição da situação de vulnerabilidade social e laboral dos sujeitos.
\end{abstract}

Palavras-chave: catadores de materiais recicláveis; análise de redes sociais; capital social; trabalho; associação de trabalhadores.

\section{RESUMEN}

El artículo objetivó investigar la formación de redes sociales de trabajo y el fomento de capital social entre miembros de una asociación de recolectores de materiales reciclables. Por medio de entrevistas y del uso de software especializado, se realizó un mapeo de las redes sociales de seis participantes. Los resultados mostraron que las redes de los asociados se caracterizan por un alto nivel de homofilia de parentesco, con la presencia sobre todo de lazos fuertes y con alto índice de localismo. La familia, amigos y vecinos ofrecen más beneficios que el hecho de estar asociados, estando en esas relaciones la mayor fuente de apoyo y recursos. Las características de las redes sociales de los asociados, a saber, con significativo localismo, homofilia, poca diversificación y sin interacción entre los trabajadores, revelan un contexto de trabajo que no ofrece subsidios para la disminución de la situación de vulnerabilidad social y laboral de los sujetos.

Palabras clave: colectores de materiales reciclables; análisis de redes sociales; capital social; trabajo; asociación de trabajadores.

\begin{abstract}
The aim of this research was to investigate the formation of social networks of work, and the consequent promotion of social capital among members of an association of collectors of recyclable materials. A mapping of the social networks of six participants was done through interviews and the use of specialized software. The results showed that the networks of the associates presented a high level of homophilia, mainly presenting strong ties and a high index of localism. Family, friends and neighbors offer more benefits than the association, given that these relationships represent the greatest source of support and resou-rces for the waste collectors. The characteristics of the members' social networks, such as significant localism, homophilia, little diversification and no interaction among workers, reveal a work context that does not offer subsidies for the reduction of the social and labor vulnerability of the subjects.
\end{abstract}

Keywords: street waste collectors; social networks analysis; social capital; work; worker's association 


\section{Introdução}

A produção de resíduos é um fenômeno característico do homem desde que esse passou a se agrupar. Porém, a expansão capitalista impulsionou uma mudança nos hábitos de consumo da população que gerou um considerável aumento no número de resíduos usados e descartados (Gonçalves, 2008), acumulando-se em forma de lixo. O aumento da produção de lixo impeliu o surgimento de uma nova categoria de trabalho: os catadores.

Desde 2002, a atividade catador de material reciclável é reconhecida pela Comissão Brasileira de Ocupações, que formaliza a Classificação Brasileira de Ocupações (CBO), e os catadores são definidos, segundo o Ministério do Trabalho e Emprego (MTE, 2002), como pessoas que catam, selecionam e vendem materiais recicláveis.

De acordo com dados do Instituto de Pesquisa Econômica Aplicada (IPEA, 2013), estima-se que, no Brasil, entre 400 mil e 600 mil pessoas trabalhem como catadores. A atividade apresenta-se como uma alternativa de trabalho diante do desemprego prolongado e tem como características exaustivas horas de trabalho e instabilidade de renda, o que provoca um sentimento de insegurança constante (Braga, Lima, \& Maciel, 2015).

Pesquisas apontam que a formação de redes sociais pode estar associada a situações laborais variadas (Cockell \& Perticarrari, 2011; Lima \& Conserva, 2006; Santos, Maciel, \& Sato, 2014; Sato, 2012), diminuindo a vulnerabilidade e proporcionando estratégias que facilitam o trabalho. Diante desse contexto e da situação de extrema precariedade social e econômica dos catadores, as redes sociais podem proporcionar estratégias que facilitam e otimizam o trabalhado desses sujeitos.

Segundo Lima e Conserva (2006, p. 75) "as redes podem ser consideradas como um conjunto de relações construídas pelos indivíduos a partir do meio social originário, através das quais se manifestam condicionamentos sociais sobre os quais elas atuam, transformando-os na busca da resolução de problemas cotidianos". Para Wasserman e Faust (1994), as redes sociais são caracterizadas por conjunto de nós, denominados de atores, que podem representar pessoas, grupos ou instituições que estabelecem interações estáveis ou duradouras o suficiente para permitir o estabelecimento de trocas. Além disso, as redes podem ser importantes aos sujeitos pois são caracterizadas por espaços onde há difusão de informação.
A teia constituída pelas redes sociais possibilita que as pessoas se beneficiem das múltiplas relações estabelecidas pelos membros que compõem a sua rede. Assim, por exemplo, quando se tem um amigo que tem um amigo que possui influência e/ou poder, podese ser beneficiado por essa relação. Nesse sentido, as pessoas inseridas na rede podem servir de ponte para se conhecer e acessar outras pessoas diferentes, de modo a ampliar a rede e, consequentemente, as possibilidades de recursos e benefícios proporcionados por ela (Meneses, 2010). Por isso, o acesso à estrutura de oportunidades pode estar mediado, entre outras coisas, pelas redes sociais nas quais o indivíduo está inserido (Marques, 2007).

O benefício advindo do pertencimento a uma rede pode ser denominado de capital social (Portes, 2000). O conceito de capital social reflete as características positivas da sociabilidade e ressalta uma fonte não monetária de poder e influência. A ideia principal é que o envolvimento e a participação de um sujeito em um grupo podem resultar em consequências positivas para ele (Portes, 2000).

Segundo Bourdieu (1980, p. 2, tradução livre), "capital social é o conjunto de recursos atuais ou potenciais que são ligados à posse de uma rede durável de relações mais ou menos institucionalizadas de conhecimento ou reconhecimento mútuo". O autor centra-se nos benefícios colhidos na construção de laços sociais ao participar e/ou manter relações com grupos.

Portes (2000) aponta três funções básicas do capital social que podem ser aplicadas a diversos contextos: fonte de controle social, fonte de apoio familiar e fonte de benefícios através de redes extrafamiliares. Lima e Conserva (2006) destacam o acesso a melhores recursos e canais de informações promovidos pelo capital social. Já Cattell (2001) reconhece o apoio social recebido muitas vezes por familiares, amigos e vizinhos também como uma forma de capital social, uma vez que promove benefícios e melhorias na qualidade de vida dos sujeitos. Para Marques (2007), o conceito diz respeito às redes de relações que possibilitam aos sujeitos acesso a recursos e apoio.

O capital social dos sujeitos, constituído em seus relacionamentos do cotidiano, possibilita o acesso a informações relevantes para a sua inserção no mercado de trabalho. Quanto maior a diversidade das redes sociais em que o sujeito está inserido, maior tende a ser o seu capital social (Lima \& Conserva, 2006). $\mathrm{O}$ volume do capital social que alguém tem depende diretamente da rede de relações que a pessoa pode mobilizar e do volume do capital econômico, cultural 
e/ou simbólico possuído por cada um dos integrantes da rede de relações (Bourdieu, 1980).

As relações podem ser divididas em dois tipos de laços: fortes e fracos (Granovetter, 1973). Os laços fracos, por serem mais superficiais, têm um alcance mais extenso, referem-se às pessoas da rede com as quais o sujeito não é tão próximo, mas que, ainda assim, se relaciona. A presença desses laços facilita o acesso a novas oportunidades, pois essa relativa falta de proximidade significa que esse indivíduo tem, provavelmente, acesso a novas informações e recursos. Já os laços fortes, caracterizados por relações de maior proximidade, tendem a ser formados por pessoas da mesma estrutura social, o que não estimula o acesso a contatos diferentes daqueles já estabelecidos.

Marques (2007, p. 36) apresenta e nomeia duas propriedades relativas às redes: localismo e homofilia. Localismo refere-se "à proporção dos nós de uma dada rede pessoal que habitam o mesmo local que o ego". Assim, localismo refere-se ao atributo "mesmo lugar de moradia", entre indivíduos que se relacionam. Essa propriedade alude a pessoas na rede de um determinado indivíduo que moram no mesmo lugar que ele. O nível localismo permite compreender se o indivíduo participa ou não de redes que contemplam contextos mais amplos. Já o conceito de homofilia reporta-se à tendência das pessoas de construir e manter contatos mais frequentes com sujeitos que apresentam características sociais similares às suas. Tanto o localismo quanto a homofilia são características que, de certo modo, levam aos laços fortes de Granovetter (1973) e significam, portanto, uma menor oportunidade de acesso a novos recursos.

Apesar da estrutura social à qual o sujeito pertence exercer importante influência sobre a formação de sua rede, sua ação individual the fornece liberdade de escolhas e de estratégias que lhe permitem mobilidade social, profissional e espacial. Desse modo, a participação em grupos diversos e o investimento em determinadas relações, entre outras iniciativas, podem favorecer ao sujeito o acesso a recursos diferenciados, o que possibilita que pessoas com a mesma origem social construam trajetórias diferentes, deslocando-se na estrutura social (Fontes \& Eichner, 2004).

As redes sociais apresentam-se como um fator importante na inserção no mercado de trabalho por parte de trabalhadores de baixa escolaridade e baixa qualificação, influenciando de diversas formas a vida laboral desses sujeitos, seja no acesso ao primeiro emprego, seja na mobilidade dentro de empresas, seja na circulação ou permanência em atividades diversas (Lima \& Conserva, 2006). Em concordância, Portugal
(2004, p. 8) afirma que "quanto menor a escolaridade, maior o peso das relações sociais no acesso ao emprego".

\section{Objetivo}

Diante do exposto, o objetivo desta pesquisa foi investigar a formação de redes sociais de trabalho e o consequente fomento de capital social entre catadores de uma associação de catadores de materiais recicláveis. As redes foram analisadas sobretudo com foco nas interações dos membros da associação entre si, e em relação às características de homofilia (especificamente grau de parentesco) e localismo.

\section{Método}

\section{Participantes e lócus da pesquisa}

Para a realização deste trabalho, foi feita uma pesquisa de campo qualitativa em uma associação de catadores de materiais recicláveis, na cidade de Fortaleza, Ceará. Foram entrevistadas seis pessoas, dentre elas a Presidente da associação e outros cinco associados.

Dos seis catadores da associação que participaram da pesquisa, dois eram homens e quatro eram mulheres. O participante mais novo tinha 26 anos e o mais velho 53 anos de idade. Todos disseram ter frequentado a escola, mas nenhum chegou a concluir o ensino fundamental. Cinco deles fazem parte da Associação há mais de 10 anos, sendo a Presidente a única que está lá desde a sua fundação (14 anos).

\section{Coleta dos dados}

Para a caracterização das redes sociais, foram realizadas entrevistas em que os participantes foram questionados, individualmente, sobre quem eram as pessoas que eles consideravam importantes e que, de alguma forma, contribuíam para a realização de seus trabalhos como catadores de materiais recicláveis. Em seguida, foram coletados dados sobre as pessoas citadas, tais como: bairro de moradia, tipo de relacionamento (se amigo, vizinho, familiar etc.), se é catador também ou não. Essas redes se configuram como redes egocentradas com conexões, como definido por Hanneman (2001).

\section{Análise dos dados}

Foi utilizada a ferramenta de Análise de Redes Sociais (ARS) para o mapeamento dos dados (Wasserman \& Faust, 1994), com o auxílio dos 
softwares UCINET e NetDraw (Borgatti, Everett, \& Freeman, 2002), que permitiram que as informações fossem desenhadas em formato de rede. As redes sociais dos participantes foram traçadas a partir das informações coletadas nas entrevistas. A ARS permite a identificação de padrões de relacionamentos e dos atores mais influentes nas redes, possibilita também a representação das interações dos indivíduos de forma ilustrativa e a consequente visualização dos seus nós, seus alcances, suas distâncias, seus fluxos.

As redes foram ilustradas a partir de três elementos básicos: nós, vínculos e fluxos. Os nós são as pessoas ou os grupos que se relacionam em torno de um objeto comum, cuja soma indica o tamanho da rede. Os nós são representados no desenho da rede por meio de quadrados. Os vínculos são os laços entre dois ou mais nós e são representados por meio de linhas. Os fluxos indicam a direção do vínculo, podendo ser unidirecionais ou bidirecionais. Eles são representados por meio de uma seta que indica o sentido do fluxo (Alejandro \& Norman, 2005).

\section{Aspectos éticos}

A pesquisa foi realizada seguindo os padrões éticos, respeitando as normas de pesquisa envolvendo seres humanos, preservando a identidade dos participantes. A coleta de dados foi executada somente após sua aprovação pelo Comitê de Ética em Pesquisa. Todos os participantes foram informados sobre os objetivos da realização do trabalho e, uma vez tendo aceitado participar, assinaram o Termo de Consentimento Livre e Esclarecido.

\section{Resultados}

Com o intuito de preservar a identidade dos entrevistados, seus nomes permanecerão em sigilo neste artigo e aqui serão denominados de Associado 1 a 5 e Presidente (da associação). Optou-se por preservar também o nome da associação que aqui será chamada de a Associação.

A Associação existe há 14 anos e tem cerca de 20 membros cadastrados. Dentre esses, quase todos têm uma outra fonte de renda, sendo essa, para muitos deles, a catação e a venda de material reciclável para depósitos de reciclagem. No momento, a Associação não compra material nem mesmo de seus próprios catadores, funcionando unicamente com a coleta, separação e venda de material recebido através de doações que, em sua maioria, provêm de empresas, instituições e residentes de Fortaleza (CE).
Durante as entrevistas, a Presidente da Associação afirmou que a principal ajuda que ela recebia para a realização de seu trabalho eram as doações realizadas por diversas empresas e por moradores que juntavam o material reciclável de suas casas e doavam àAssociação. Além das empresas, ela citou a importância do projeto E-Coelce, da Rede de Catadores, do Fórum Lixo e Cidadania e do Movimento Nacional dos Catadores de Materiais Recicláveis. Nenhum outro entrevistado fez referência em nenhum momento a algum desses "grupos". Por não serem pessoas, optou-se por não inseri-los nos desenhos de redes apresentados a seguir, mas, sem dúvida, o fato de apenas a Presidente tê-los citado representa uma importante informação para o entendimento da rede e do funcionamento geral da Associação.

\section{As redes e o capital social dos catadores entrevistados}

As redes de cada participante foram reunidas em um só desenho, onde suas informações foram cruzadas e ilustradas através dos softwares UCINET e NetDraw. O desenho da rede possibilita uma visualização mais clara de sua estrutura, características e peculiaridades. A seguir, são apresentadas três figuras com desenhos das redes com formatos iguais, porém com cores diferentes (Figuras 1 a 3 ). As cores foram selecionadas de modo a ressaltar aspectos distintos das redes. Isso significa que cada figura apresenta cores específicas que ressaltam características específicas daquela ilustração.

\section{Figura 1. Rede de relações principais da Associação estudada}

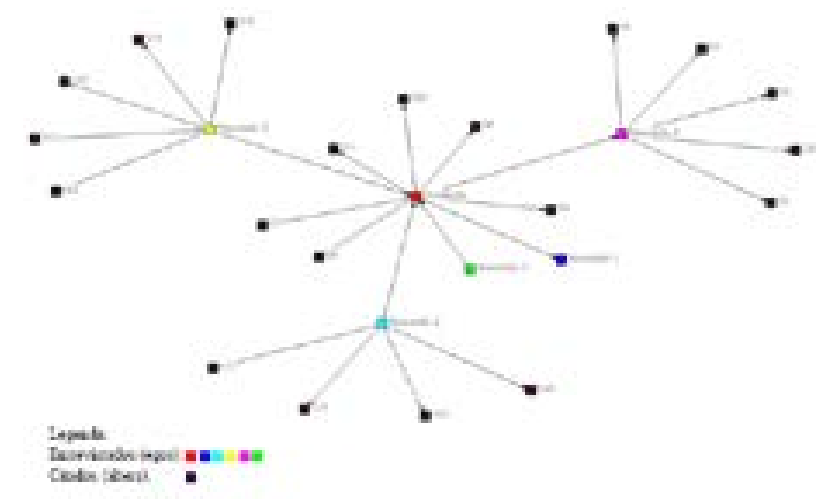

O mapeamento das redes entrelaçadas, apresentado na Figura 1, demonstra a presença de 26 atores (nós), sendo 6 deles participantes da pesquisa. Percebe-se que os entrevistados, embora façam parte de uma mesma associação, e por isso poderia se deduzir 
que são importantes uns para os outros, não se citaram como "pessoas que eles consideravam importantes e que, de alguma forma, contribuíam para a realização de seus trabalhos". Os dados apontam que são pessoas de fora da associação as mais importantes para que eles realizem o seu trabalho. A exceção foi a Presidente, o único membro da Associação citado por todos. Aparentemente, os laços entre os associados parecem ser pouco significativos ou nem sequer existem.

Dentre as pessoas citadas pelos participantes, a grande maioria era considerada um amigo ou fazia parte de sua família. A Figura 2 mostra o elevado índice de homofilia relacionada ao atributo "parentesco". Os componentes das redes apresentam, em sua maioria, algum parente na rede. Como pode ser observado, as redes dos Associados 1, 2 e 5 são compostas inteiramente por pessoas que apresentam algum parente na rede.

\section{Figura 2. A rede de relações segundo o atributo parentesco (homofilia)}

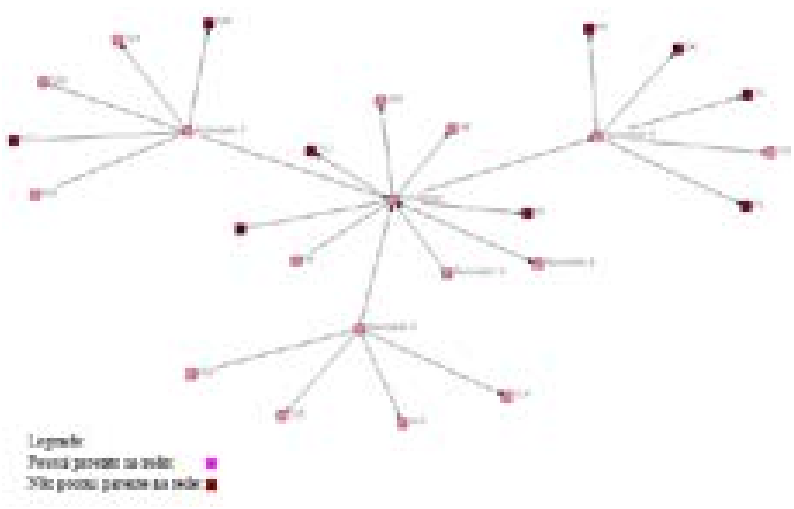

Segundo os participantes, essas pessoas são importantes sobretudo por oferecerem ajuda em momentos de dificuldade, como em questões emocionais ou por poder "contar sempre que preciso" com elas. Esse tipo de laço é classificado como laço forte (Granovetter, 1973) e costuma representar um capital social importante, sobretudo na forma de apoio social.

A Figura 3 mostra o alto nível de localismo das redes. É possível perceber que os laços estão ancorados principalmente na vizinhança, mostrando como a territorialidade, por questões sociais e espaciais, é importante na construção das redes. O localismo parece ser uma característica das redes de sujeitos em situações de pobreza, talvez pela dificuldade de acessar e se inserir em outros espaços. Corroborando os achados de Marques (2007) com populações pobres de São Paulo, as redes dos catadores entrevistados são pouco diversificadas, apoiando-se sobretudo na vizinhança (onde geralmente estão também familiares e amigos).

Todas as pessoas da rede da Associada 4, por exemplo, pertencem ao mesmo bairro (representado pela cor vermelha); o mesmo acontece com a Associada 2. O Associado 3 relaciona-se sobretudo com pessoas de seu bairro (cor verde), excetuando-se sua relação com a Presidente (cor vermelha).

\section{Figura 3. A rede de relações segundo o atributo moradia (localismo)}

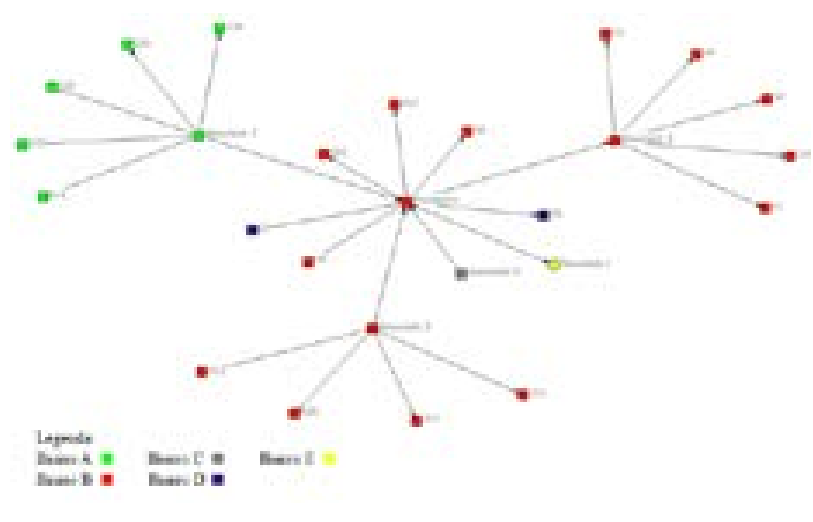

A Presidente, entre os entrevistados, é a que apresenta maior número de relações com pessoas de outros bairros, o que demonstra que o localismo de sua rede egocentrada é o menor. Além disso, é na rede dela que estão os sujeitos S6 e S7, os únicos que moram em bairros mais distantes dos demais. Nenhum dos dois é catador, nem apresenta parentesco com alguém da rede, sendo importantes fontes de capital social. S6 é uma pessoa vinculada a uma instituição que presta uma assessoria à associação, colaborando em atividades mais burocráticas. Além disso, sua instituição financia atividades da associação, como viagens a Encontros e Congressos de catadores de materiais recicláveis a nível nacional. S7 é uma engenheira ambiental que trabalha em parceria com diversas empresas da cidade de Fortaleza e sempre indica a Associação para receber a doação de materiais recicláveis dessas empresas. Ela é um exemplo bastante explicativo da importância dos laços fracos, pois essa pessoa nunca foi até a associação, não tem contato com nenhum associado, com exceção da Presidente, conheceu o trabalho da Associação pela internet e fez os primeiros contatos por telefone com o intuito de doar materiais recicláveis. A relação que mantém com a Presidente é exclusivamente no sentido de apresentá-la a empresas que desejam cooperar com a coleta seletiva de materiais. Percebe-se como 
esse laço fraco fornece um alcance mais extenso à rede, possibilitando à Presidente entrar em contato com empresas totalmente distantes de seu contexto socioeconômico e geográfico.

O capital social, que gera acesso a novos contatos, informações, melhores mercados e condições de trabalho, aparece centralizado na Presidente, pois é perceptível uma maior heterogeneidade em sua rede, com laços fortes e fracos, e contatos com maior variabilidade. Nesse sentido, a rede social da Presidente apresenta uma maior diversificação e acesso a pessoas provedoras de benefícios.

\section{Discussão}

A literatura sobre redes sugere a importância de relações heterogêneas para proporcionar acesso a recursos diversificados (Cattell, 2001; Granovetter, 1973; Lima \& Conserva, 2006; Marques, 2007; Marteleto \& Silva, 2004). Relações com pessoas semelhantes socioeconomicamente são importantes, pois em geral fornecem acolhimento e apoio, mas são insuficientes por serem canais de capital e informações redundantes.

A análise das redes dos catadores entrevistados apresenta a rede da Presidente como a mais diversificada quanto aos seus laços. A sua rede, por ser composta por um maior número de atores, oferece uma gama de recursos mais variada. Quando ela não pode contar com uma pessoa, é possível tentar acionar uma outra. O contrário é observado no caso das redes dos associados 1 e 5 , por exemplo, compostas unicamente por uma pessoa, o que sugere uma limitação, pois eles ficam restritos à ajuda de um único contato.

A ausência na rede dos associados de importantes fontes de capital social e a não referência em suas entrevistas das doações das empresas, do projeto E-Coelce, da Rede de Catadores, do Fórum Lixo e Cidadania e do Movimento Nacional dos Catadores de Materiais Recicláveis, bem como dos sujeitos S6 e S7 (apontados como importantes apenas pela Presidente), mostra como essas pessoas e grupos não contribuem diretamente com o trabalho dos associados e nem com sua melhoria. Apesar disso, esses laços são fundamentais para o funcionamento da Associação, pois atuam como pontos de conexão com outros atores e por isso são fontes de capital social. Através do mapeamento da rede, percebe-se que esse capital está centralizado na Presidente que, desse modo, possui um poder quase absoluto sobre ele.

Pode-se pensar na existência de um poder explícito, presente nas redes, que está vinculado à posse de bens ou recursos e ao acesso a informações privilegiadas para o exercício do trabalho (Lima \& Conserva, 2006). Percebe-se, diante disso, como a Presidente, por concentrar em sua rede contatos como os sujeitos S6 e S7, além de ser a única associada que mantém contato com as empresas doadoras, tem um poder explícito em suas mãos. Uma vez que a Associação vive unicamente de doações e ela é a ponte entre as empresas e os contatos que fornecem as doações, ela possui o controle sobre informações privilegiadas, sem as quais a Associação dificilmente se manteria. De maneira ideal, a posse dessas informações deveria ser compartilhada com os demais associados e servir para a ampliação do capital social de todos. Mas isto não parece ocorrer. Os outros participantes da pesquisa não parecem contar, de maneira direta, com esses recursos para a realização de seus trabalhos, que os coloca em uma posição mais periférica, com menos influência nas trocas e menos poder na rede (Mizruchi, 2006).

Uma vez que a quantidade de capital social está diretamente relacionada com a diversidade da rede (Lima \& Conserva, 2006) e que esse mesmo capital é influenciado pelo volume de capital econômico, cultural e simbólico que circula (Bourdieu, 1980), pode-se refletir que as redes dos participantes, em geral, são pobres no que se refere ao oferecimento de capital social uns para os outros.

As relações que dão suporte e se mostram significativas para os outros associados são, sobretudo, aquelas mantidas com pessoas da família, amigos próximos e vizinhos, o que significa que esses indivíduos possuem um capital social restrito em termos de recursos. Esses laços, caracterizados como fortes, apesar de terem limitações, também são provedores de benefícios, caracterizando relações de trocas de lealdade, compromisso com o outro e solidariedade. Essas características configuram a sobreposição de laços ou multiplexidade, comum nos laços fortes, cujos relacionamentos costumam ser mais fechados (Lemieux \& Ouimet, 2012). Esses associados têm em suas redes contatos que propiciam o capital social na forma de apoio social, sendo esse tipicamente fornecido a partir das relações primárias (família, amigos e vizinhos), o que é bastante comum em situação de vulnerabilidade social e laboral (Lomnitz, 2009)

O fato de a Associação ser para muitos deles fonte de uma renda extra, e não a principal, corrobora o fato de essa apresentar-se apenas como uma fonte secundária de capital social que gera algum benefício no campo do trabalho. As redes sociais formadas pela família, amigos e vizinhança parecem oferecer mais 
benefícios do que o fato de ser associado, estando nessas ligações a maior fonte de apoio e de recursos, sejam eles materiais ou não.

Corroborando isso está o fato dos associados praticamente não terem se citado como sendo importantes para a realização dos trabalhos uns dos outros. Tal dado aponta que os membros da Associação não são uns para os outros fontes de auxílios. A precariedade de vínculos entre os associados pode gerar dificuldades na formação de canais por onde passam informações, suporte ou apoio. Por conta da centralização das relações na Presidente, infere-se que o capital social da Associação perpassa sempre esse ator, que serve como ponte de informações e benefícios para os demais associados, os quais, sozinhos, não se conectam. Apesar da existência de redes no ambiente de trabalho, a falta de interação entre os catadores aponta para a inexistência de coletivos de trabalho efetivos na Associação, o que se diferencia de outros estudos (Conserva, 2004; Sato, 2012).

Como se pode observar no desenho das redes (Figuras 1 a 3), chama a atenção o fato da rede como um todo apresentar formato em estrela, com a figura da Presidente no centro, intermediando a relação entre os demais associados e os integrantes das redes quando há uma forte centralidade de intermediariedade na rede, que é quando um ator está em posição de intermediar a conexão com outros atores (Lemieux \& Ouimet, 2012), prevalece um intenso controle sobre os fluxos de troca. Isso se mostra extremamente relevante para se entender os rumos que o capital social toma na rede, pois a posição que o sujeito ocupa permite a compreensão de suas possibilidades no acesso a bens e recursos.

Uma vez que a ideia central do capital social é que o envolvimento e a participação em grupos traz benefícios para os sujeitos (Portes, 2000), a priori poder-se-ia pensar que o fato dos catadores pesquisados estarem reunidos em uma associação garantiria a formação de uma rede social que proporcionasse melhor acesso a informações e suporte para a realização de seus trabalhos. Porém, o constatado pela pesquisa foi que a Associação não apresenta um nível de capital social suficiente para vencer a precariedade da situação de catador de recicláveis. Embora os catadores associados estejam em uma situação melhor quando comparados aos catadores que trabalham para depósitos (Maciel, Santos, Matos, Meireles, Vieira, \& Fontenelle, 2010), sua rede de relações não leva à ampliação de seu capital social. Além disso, dado que os laços que levam a conexões mais amplas e diversificadas só existem na rede da Presidente, é evidente que essa situação não se propaga nas redes dos outros associados.
Como as redes sociais têm um papel importante no que diz respeito ao acesso a emprego e melhores condições de vida, pode-se associar as limitações encontradas nas redes dos catadores participantes desta pesquisa com as dificuldades e precariedades de suas condições de trabalho e de vida. A inexistência (ou o tamanho reduzido) de canais de informação, de acesso a grupos e pessoas em condições distintas das suas que possibilitem acesso a novos contatos, dificulta a ascensão social desses sujeitos, podendo levar a um processo de estagnação e reprodução da pobreza (Guimarães, Andrada, Picanço, \& Vieira, 2012).

\section{Considerações finais}

Por meio da pesquisa, pode-se concluir que as redes sociais dos catadores entrevistados caracterizamse por um alto nível de homofilia, com a presença sobretudo de laços fortes e com elevado índice de localismo, indicando a influência do contexto social e espacial na construção das redes desses sujeitos. Esses aspectos também foram observados em outros estudos com populações de baixa renda (Fontes \& Eichner, 2004; Marques, 2007), revelando-se, possivelmente, como características das redes de indivíduos pobres.

Somados ao localismo, aos laços fortes e à homofília, pode-se destacar ainda o formato em estrela da rede e o fato dos associados não se citarem durante as entrevistas, o que permite sugerir um capital social restrito que circula pelas redes. Percebe-se a importância de se cultivar relações com sujeitos que possibilitem uma maior variabilidade de recursos no campo do trabalho, seja na forma de informação, apoio e/ou material.

Apesar dos sujeitos estarem reunidos em torno de uma associação, esta não demonstra ser uma fonte direta de recursos e benefícios para grande parte dos associados, excetuando-se a Presidente. As características das redes sociais dos associados, a saber, com significativo localismo, homofilia, pouca diversificação e sem interação entre os trabalhadores, revela um contexto de trabalho que não oferece subsídios para a diminuição da situação de vulnerabilidade social e laboral dos sujeitos. Para a maioria dos entrevistados, a família, os amigos próximos e os vizinhos são as principais fontes de apoio, recursos e benefícios.

Pode-se refletir que para a ampliação do capital social dos catadores associados é necessário que eles ampliem suas redes sociais para além de suas fronteiras sociodemográficas, estendendo seu alcance a pessoas e instituições que possam propiciar 
benefícios e melhorias na qualidade e no exercício de suas atividades, expandindo seus laços fracos. Nesse sentido, reconhece-se que "as relações sociais integram estruturas paralelas no mercado e a organização do trabalho, assumindo papel preponderante, na representação dos trabalhadores, em seus destinos profissionais e, por consequência, em sua vida pessoal" (Lima \& Conserva, 2006, p. 87).

Estudar as redes e o capital social de catadores é uma forma ainda relativamente pouco explorada para se compreender como os contatos e as relações influenciam na dinâmica do trabalho. Para estudos futuros, sugere-se aprofundar nas questões que tratam das limitações e dos benefícios concretos que essas relações podem oferecer.

\section{Referências}

Alejandro, V. \& Norman, A. (2005). Manual introdutório à Analise de Redes Sociais: Medidas de centralidade. Recuperado de http://api.ning.com/files/ib7AWBiwEwSR ilCmh7sNfwlCgobUCA5QiUqiZOskSh15AhSOE9Xhzc VRUr5JXYapSVS45I5OKOBEjoSvbD-ykrzDOcrBPq7N/ Manualintrodutorio ex ucinet.pdf

Borgatti, S. P., Everett, M. G., \& Freeman, L. C. (2002). Ucinet for Windows: Software for social network analysis. Harvard, MA: Analytic Technologies.

Bourdieu, P. (1980). Le capital social. Actes de la recherche en sciences sociales, 31, 2-3.

Braga, N. L., Lima, D. M. A., \& Maciel, R. H. (2015). "Não tinha trabalho, mas tinha reciclagem": Sentidos do trabalho de catadores de materiais recicláveis. Temas em Psicologia, 23(4), 1051-1059.

Cattell, V. (2001). Poor people, poor places, and poor health: The mediating role of social networks and social capital. Social Science \& Medicine, 52(10), 1501-1516. http:// dx.doi.org/10.1016/S0277-9536(00)00259-8

Cockell, F. F. \& Perticarrari, D. (2011). Retratos da informalidade: a fragilidade dos sistemas de proteção social em momentos de infortúnio. Ciência \& Saúde Coletiva, 16(3), 1709-1718. https://dx.doi.org/10.1590/ $\underline{\text { S1413-81232011000300008 }}$

Conserva, M. S. (2004). O labirinto da atividade ambulante na cidade de João Pessoa. In A. Araújo, M. F. Alberto, M. Y. Neves, \& M. Athayde (Orgs.), Cenários do trabalho: Subjetividade, movimento e enigma (pp. 270-272). Rio de Janeiro: DP\&A

Fontes, B. \& Eichner, K. (2004). A formação de capital social em uma comunidade de baixa renda. Revista Hispana para el Análisis de Redes sociales, 7(2), 1-33.

Gonçalves, R. C. M. (2008). A voz dos catadores de lixo em sua luta pela sobrevivência. Dissertação de Mestrado, Programa de Pós-graduação em Políticas Públicas, Universidade Estadual do Ceará, Fortaleza, CE.

Granovetter, M. S. (1973). The strength of weak ties. The American Journal of Sociology, 78(6), 1360-1380. http:// dx.doi.org/10.1086/225469

Guimarães, N. A., Andrada, A. C., Picanço, M., \& Vieira, P. (2012). Redes sociais e obtenção de trabalho: Trajetórias, atributos e relações. In E. Marques (Org.), Redes sociais no Brasil: Organizações civis e politicas públicas (pp. 211247). Belo Horizonte: Fino Traço.

Instituto de Pesquisa Econômica Aplicada [IPEA]. (2013). Situação social das catadoras e dos catadores de material reciclável e reutilizável Brasil. Brasília, DF: Autor.

Lemieux, V. \& Ouimet, M. (2012). Análise estrutural das redes sociais ( $2^{\mathrm{a}}$ ed.). Lisboa: Instituto Piaget.

Lima, J. C. \& Conserva, M. S. (2006). Redes sociais e mercado de trabalho: entre o formal e o informal. Politica e Trabalho, 24, 73-98.

Lomnitz, L. A. (2009). Redes sociais, cultura e poder. Rio de Janeiro: E-papers.

Maciel, R. H., Santos, J. B. F., Matos, T. G. R., Meireles, G. F., Vieira, M. E. A., \& Fontenelle, M. F. (2010). Work, health and organisation of street scavengers in Fortaleza, Brazil. Policy and Practice in Health and Safety, 8(2), 95-112. http://dx.doi.org/10.9788/TP2015.4-19

Marques, E. C. L. (2007). Redes sociais, segregação e pobreza em São Paulo. Tese de Livre Docência, Universidade de São Paulo, Faculdade de Filosofia, Letras e Ciências Humanas, São Paulo, SP.

Marteleto, R. M. \& Silva, A. B. O. (2004). Rede e capital social: $\mathrm{O}$ enfoque da informação para o desenvolvimento local. Ciência \& Informação, Brasília, 33(3), 41-49. http://dx.doi. org/10.1590/S0100-19652004000300006

Meneses, M. P. R. (2010). Conceitos sobre redes sociais no paradigma ecossistêmico. In J. C. Sarriera, \& E. T. Saforcada (Orgs.), Introdução à psicologia comunitária: Bases teóricas e metodológicas (pp. 97-112). Porto Alegre: Sulina.

Ministério do Trabalho e Emprego [MTE]. Classificação Brasileira de Ocupações. Recuperado de http://www. mtecbo.gov.br/cbosite/pages/home.jsf

Mizruchi, M. S. (2006). Análise de redes sociais: avanços recentes e controvérsias atuais. Revista de Administração de Empresas, 46(3), 72-86. https://dx.doi.org/10.1590/S003475902006000300013

Portes, A. (2000). Capital social: Origens e aplicações na sociologia contemporânea. Sociologia, problemas e práticas, 33, 133-158.

Portugal, S. (2006). Quanto vale o capital social? O papel das redes informais na provisão de recursos. In P. H. Martins \& B. Fontes (Orgs.), Redes, práticas associativas e gestão pública (pp. 39-60). Recife: Editora Universitária da UFPE.

Santos, J. B. F., Maciel, R. H., \& Sato, L. (2014). Trabalhadores informais e a formação de redes socioprodutivas (RSP): Considerações teórico-empíricas. Contemporânea, 4(2), 325-350. Recuperado de http://www.contemporanea.ufscar. br/index.php/contemporanea/article/view/251

Sato, L. (2012). Feira livre: Organização, trabalho $e$ sociabilidade. São Paulo: Editora da Universidade de São Paulo.

Wasserman, S. \& Faust, K. (1994). Social network analysis: Methods and applications. Cambridge, UK: Cambridge University Press.

Submissão em: 19/12/2016

Revisão em: 13/08/2018

Aceite em: 24/10/2018 
Agência de fomento: o presente trabalho foi realizado com apoio de uma bolsa de Mestrado, concedida pelo Fundo de Inovação Tecnológica FIT (2014/2015), da Fundação Cearense de Apoio ao Desenvolvimento Científico e Tecnológico - FUNCAP.

Natalia Lopes Braga é graduada em Psicologia pela Universidade de Fortaleza (2009). Especialista em Psicologia Social e Comunitária pela FATECI (2013). Mestre em Psicologia pela Universidade de Fortaleza (2015). Doutoranda em Psicologia pela Universidade de Fortaleza, início em 2015. Membro do Laboratório de Estudos sobre o Trabalho (LET). Pesquisadora trabalhando principalmente com os temas: Associações e cooperativas de trabalhadores, Redes sociais, Trabalho informal, Psicologia Social Crítica. http://orcid.org/0000-0002-8619-7208

Endereço para correspondência: LET- UNIFOR. Av. Washington Soares, 1321. Edson Queiroz. Fortaleza/CE, Brasil. CEP: 60811-905.

E-mail: nataliabraga1@gmail.com
Regina Heloisa Maciel é graduada em Psicologia pela Universidade de São Paulo (1977), mestrado em Applied Psychology Ergonomics - University Of Wales Institute

Of Science And Techonology (1981) e doutorado em Psicologia (Psicologia Experimental) pela Universidade de São Paulo (1991). Coordena o Núcleo de Estudos sobre o Trabalho e o Laboratório de Estudos sobre o Trabalho (LET) do Programa de Pós-graduação em Psicologia da UNIFOR. Faz parte da Rede Observatório em Recursos Humanos, estação Ceará (ROREHS-CE). Editora da Revista Subjetividades (antiga Mal-estar e Subjetividade). Atua principalmente nos temas ergonomia, condições de trabalho, saúde do trabalhador, assédio moral no trabalho e burnout. http://orcid.org/0000-0003-2933-7021 E-mail: reginaheloisamaciel@gmail.com

Renata Guimarães de Carvalho é graduada em Psicologia pela Universidade Federal do Ceará - UFC (1997), mestrado em Administração pela Universidade Estadual do Ceará UECE (2001) e doutorado em Psicologia pela Universidade de Fortaleza - UNIFOR (2016). É professora do curso de Psicologia da Universidade Federal do Ceará - UFC, Campus Sobral. http://orcid.org/0000-0002-3592-7709 E-mail: renatagui74@yahoo.com.br 